\title{
Efektifitas Penilaian Kinerja Karyawan Dalam Peningkatan Motivasi Kerja Menerapkan Metode Rank Order Centroid (ROC) dan Additive Ratio Assessment (ARAS)
}

\author{
Mesran' ${ }^{1}$, Joli Afriany' ${ }^{2}$, Syafrida Hafni Sahir ${ }^{3}$ \\ ${ }^{1}$ STMIK Budi Darma, Medan, Indonesia \\ ${ }^{2}$ Universitas Nahdlatul Ulama Sumatera Utara, Medan, Indonesia \\ ${ }^{3}$ Universitas Medan Area, Medan, Indonesia \\ Email: mesran.skom.mkom@gmail.com, joliafriani@gmail.com,syahaf@yahoo.com
}

\begin{abstract}
The quality of a company can be seen from the quality of the resources contained in the company. In improving the quality of employee resources. One way to see the quality of employees is by evaluating the performance produced by employees. Another benefit of this performance appraisal is that employees will be motivated to work well because, for employees who have poor performance scores, sanctions or reprimand can be given. To assess employee performance, a good system is needed. This system is expected to be objective in carrying out assessments. In this study, a decision support system was used by applying the Additive Ratio Assessment (ARAS) method. In order for the calculation results to be more specific, the weights are generated using the Centroid Order Rank (ROC) method. It is expected that the results of the study can help decision-makers in the assessment of employee performance.
\end{abstract}

Keywords: Employee Performance, Assessment, Information Systems, ROC, ARAS

Abstrak- Kualitas suatu perusahaan, dapat dilihat dari kualitas sumber daya yang terdapat pada perusahaan tersebut. Dalam meningkatkan kualitas sumber daya karyawan. Salah satu cara untuk melihat kualitas karyawan dengan melakukan penilaian terhadap kinerja yang dihasilkan karyawan. Manfaat lain dari penilaian kinerja ini, yaitu karyawan akan termotivasi untuk bekerja dengan baik, karena bagi karyawan yang memiliki nilai kinerja yang buruk, maka akan dapat diberikannya sanksi ataupun surat teguran. Untuk menilai kinerja karyawan maka dibutuhkan sistem yang baik. Sistem ini diharapkan dapat bersifat objektif dalam melakukan penilaian. Pada penelitian ini digunakan sistem pendukung keputusan dengan menerapkan metode Additive Ratio Assessment (ARAS). Agar hasil perhitungan menjadi lebih spesifik, maka bobot dihasilkan dengan menggunakan metode Rank Order Centroid(ROC). Diharapkan hasil penelitian mampu membantu pengambil keputusan dalam penilaian kinerja karyawan.

Kata Kunci: Kinerja Karyawan, Penilaian, Sistem Informasi, ROC, ARAS

\section{PENDAHULUAN}

Perkembangan teknologi perangkat lunak semakin pesat dengan menyeimbangkan terhadap perkembangan dari perangkat keras komputer. Sudah merupakan suatu kebutuhan dasar saat ini bagi perusahaan dalam penggunaan komputer yang dapat melakukan efisiensi kerja bagi pimpinannya. Termasuk salah 
satunya dalam melakukan penilaian terhadap kinerja karyawan. Kinerja karyawan merupakan hasil yang diberikan karyawan terhadap pekerjaan yang dilakukannya. Hal ini terlihat dari kecakapan dalam menyelesaikan pekerjaan, tanggung jawab yang diberikan, kualitas dari hasil hasil suatu pekerjaan, waktu yang dibutuhkan dalam menyelesaikan pekerjaannya serta banyak lagi kriteria yang dibutuhkan manajemen dalam menilai kinerja dari karyawan. Karyawan merupakan faktor pendukung dalam sebuah perusahaan atau instansi, karena dengan adanya karyawan yang memiliki standar kualifikasi perusahaan maka produktivitas meningkat[1]. Keberhasilan perusahaan dalam beroperasi, tentu tidak terlepas dari kinerja para karyawannya, agar setiap karyawan dapat memberikan benefit yang menguntungkan perusahaan, tentu perusahaan harus dapat memberikan dampak yang terbaik bagi karyawannya. Ini merupakan motivasi yang baik bagi karyawan untuk dapat memberikan kinerja yang semakin baik. Motivasi yang diberikan kepada karyawan nantinya bisa berupa kenaikan gaji, pemberian insentif atau promosi jabatan[2]. Sehingga dalam hal tersebut penilaian terhadap kinerja karyawan perlu dilakukan untuk mengetahuin hasil kinerja bagi masing-masing karyawan. Agar penilaian tersebut lebih efektif, maka untuk menilai kinerja karyawan dibutuhkan teknologi perangkat lunak, dalam hal ini di kenal dengan nama sistem informasi berbasis pendukung keputusan. Walaupun manajemen dapat memberikan keputusan terhadap kinerja dari karyawannya, namun tentunya penilaian tersebut bersifat subyektik, karena masih penilaian secara personal, bukan secara obyektif. Agar penilaian kinerja karyawan bersifat objektif, maka dibutuhkan sistem pendukung keputusan (SPK) yang dapat memberikan hasil keputusan yang terbaik[3]-[5]. Hingga saat ini penerapan sistem pendukung keputusan terhadap manajemen keputusan di dalam perusahaan begitu dibutuhkan, dan semakin berkembang.

Dalam penerapannya, keputusan yang dihasilkan oleh sistem pendukung keputusan menggunakan metode metode tertentu. Sehingga informasi yang dihasilkan menjadi lebih baik. Beberapa metode pendukung keputusan yang biasa digunakan diantaranya pengefektifan keputusan menggunakan metode TOPSIS[6], pemilihan lokasi laptop menggunakan preference selection index[7], peningkatan gaji karyawan menggunakan metode SAW [8], penentuan lokasi[9]. Beberapa penelitian yang pernah dilakukan dalam menyelesaikan permasalahan menerapkan sistem pendukung keputusan, seperti yang dilakukan oleh Yehezkiel Fernando pada tahun 2017. Hasil penelitian yang berjudul sistem pendukung keputusan penilaian kinerja karyawan menggunakan metode WP, memberikan keputusan yang objektif. Sehingga pihak personalia mampu menghasilkan keputusan dengan cepat dan tepat[1]. Pada tahun 2015, Kevin Tangkuman menghasilkan penelitian bahwa pengaruh hasil penelitian kinerja karyawan terhadap reward, punishment sangat baik, karyawa akan menjadi termotivasi dalam bekerja[10]. Berdasarkan dari penjelasan di atas, maka peneliti tertarik untuk melakukan penelitian dalam menghitung kinerja karyawan menggunakan sistem pendukung keputusan dengan menerapkan metode ARAS yang 
dikombinasikan dengan metode ROC dalam menghasilkan nilai bobot, sehingga hasil penelitian bermanfaat bagi manajemen dalam peningkatan kinerja karyawan.

\section{METODOLOGI PENELITIAN}

\subsection{Sistem Pendukung Keputusan}

Sistem pendukung keputusan merupakan perangkat lunak berbasis komputer yang memiliki kemampuan spesifik untuk menghasilkan keputusan yang terbaik bagi manajemen, dalam penyelesaian masalah yang dihadapi[5], [11]. Pada penerapan SPK, membutuhkan database-database, sebagai dasar dalam menghasilkan keputusan.

\subsection{Kinerja Karyawan}

Kinerja karyawan, merupakan hasil yang bisa diperoleh bagi karyawan setelah menyelesaikan pekerjaannya. Kinerja karyawan akan terlihat dari waktu pelaksanaan pekerjaan, perangkat yang dibutuhkan, kualitas pekerjaan yang dihasilkan [10].

\subsection{Rank Order Centroid (ROC)}

Untuk menghasilkan keputusan yang tepat, tentu didukung oleh bobot yang ideal. Dalam penelitian, bobot terhadap kriteria akan di hasilkan menggunakan metode Rank Order Centroid(ROC). Metode ROC merupakan metode yang menitik beratkan terhadap prioritas kriteria menjadi yang utama. Dalam hal ini, kriteria-1 merupakan prioritas yang tertinggi dibandingkan kriteria ke 2, begitu juga kriteria ke2 merupakan priotitas tertinggi bila dibandingkan kriteria ke 3, selanjutnya dilakukan langkah yang sama hingga pritoritas kriteria yang terendah [12]. Hal ini dapat dilihat pada persamaan ke 1 .

$\mathrm{Cr}_{1} \geq \mathrm{Cr}_{2} \geq \mathrm{Cr}_{3} \geq \ldots \geq \mathrm{Cm}_{\mathrm{m}}$

Sehingga setelah di proses akan menghasilkan:

$\mathrm{W}_{1} \geq \mathrm{W}_{2} \geq \mathrm{W}_{3} \geq \ldots \geq \mathrm{C}_{\mathrm{m}}$

Untuk mendapatkan nilai bobot(W), maka digunakan persamaan ke 3, sebagai berikut:

$W_{m}=\frac{1}{m} \sum_{1=1}^{m}\left(\frac{1}{i}\right)$

Hasil dari total $\mathrm{W}_{\mathrm{m}}$, yaitu berinilai 1 .

\subsection{Metode Additive Ratio Assessment (ARAS)}

Pada penelitian ini digunakan metode Additive Ratio Assessment (ARAS). ARAS merupakan sebuah metode yang digunakan untuk perangkingan kriteria, dalam melakukan proses perangkingan. Tahapan yang digunakan dalam metode ARAS[13][15], yaitu: 
Langkah-1: Pembentukan Decision Making Matrix

$$
X=\left[\begin{array}{cccc}
X 01 & X 0 j & \cdots & X 0 n \\
X i 1 & X i j & \cdots & X i n \\
\vdots & \vdots & \ddots & \vdots \\
X n 1 & X m j & \cdots & X m n
\end{array}\right](i=0, \mathrm{~m} ; \ldots j=1, \mathrm{n})
$$

Dimana

$\mathrm{m}=$ jumlah alternatif

$\mathrm{n}=$ jumlah kriteria

$x_{i j}=$ nilai performa dari alternatif $i$ terhadap kriteria $j x_{0 j}=$ nilai optimum dari kriteriaj

Jika nilai optimal kriteria $\mathrm{j}(X 0 j)$ tidak diketahui, maka:

$X 0 j=\frac{\max }{i}$.Xij, if $\frac{\max }{i} . X i j$ is preferable

$X 0 j=\frac{\min }{i} . X i j$, if $\frac{\min }{i} . X i j$ is prefable

Langkah-2: Penormalisasian matriks keputusan untuk semua kriteria Jika kriteria Beneficial maka dilakukan normalisasi mengikuti:

$X i j^{*}=\frac{X i j}{\sum_{i=0}^{m} X i j}$

Dimana $X i j^{*}$ adalah nilai normalisasi.

Jika kriteria Non-Beneficial maka dilakukan normalisasimengikuti:

Tahap 1: $X i j^{*}=\frac{1}{X i j}$

Tahap 2: $R=\frac{X i j^{*}}{\sum_{i=0}^{m} X i j^{*}}$

Langkah-3: Menentukan bobot matriks yang sudah dinormalisasi

$D=[d i j] m x n=r i j . W j$

Dimana

$\mathrm{Wj}=$ bobot kriteria $\mathrm{j}$

Langkah 4: Menentukan nilai dari fungsi optimalisasi (Si)

$S i=\sum_{j=1}^{n} \operatorname{dij} ;(i=1,2 \ldots, m ; j=1,2 \ldots, n)$

Dimana $S i$ adalah nilai fungsi optimalitas alternatif i. Nilai terbesar adalah yang terbaik, dan nilai yang paling sedikit adalah yang terburuk. Dengan memperhitungkan proses,hubungan proporsional dengan nilai dan bobot kriteria yang diteliti berpengaruh pada hasil akhir. 
Langkah 5: Menentukan tingkatan peringkat tertinggi dari alternatif $U i=\frac{S i}{S 0}$

Dimana $S i$ dan $S 0$ merupakan nilai kriteria optimalitas, diperoleh dari persamaan. Sudah jelas, itu dihitung nilai $U i$ berada pada interval [0,1] dan merupakan pesanan yang diinginkan didahulukan efisiensi relatif kompleks dari alternatif yang layak bisa ditentukan sesuai dengan nilai fungsi utilitas.

\subsection{Kerangka Penelitian}

Penelitian ini, terdiri dari beberapa tahapan, diantaranya:

a. Studi Literatur

Pada tahapan ini, dilakukan pemahaman terhadap objek yang akan diteliti, dengan membaca buku-buku, ataupun sumber bacaan yang lain.

b. Tahapan Analisa Masalah

Tahapan Analisa masalah bertujuan untuk mengetahui sumber masalah yang terjadi. Sehingga penyelesaian yang dihasilkan diharapkan nantinya dapat mengatasi permasalahan yang ada.

c. Tahapan Pengujian Metode

Pengujian metode ditujukan untuk menghitung nilai nilai dari setiap alternatif dan kriteria yang ada.

d. Pembuatan laporan akhir penelitian

Tahapan akhir dari penelitian ini, yaitu mengumpulkan semua data, bahan serta hasil pengujian yang dituangkan kedalam bentuk laporan penelitian.

\section{HASIL DAN PEMBAHASAN}

Penilaian kinerja mutlak dibutuhkan bagi manajemen, hal ini bertujuan agar manajemen bisa memberikan tanggung jawabnya terhadap hasil pekerjaan yang dilakukan bagi setiap karyawannya. Disisi lain, perusahaan bisa memberikan peringatan/tekanan bagi karyawan yang tidak bekerja dengan baik dengan surat pemberitahuan. Tentunya untuk karyawan yang memiliki kinerja yang baik, perusahaan harusnya mampu memberikan motivasi terhadap karyawannya. Untuk menentukan penilaian kinerja karyawan, pada penelitian ini, dibutuhkan kriteria kriteria sepertitanggungjawab, kerjasama, kualitas hasil pekerjaan, kedisiplinan, pelaporan.Kriteria tersebut dapat dilihat pada tabel 1, berikut ini.

Tabel 1. Kriteria penilaian kinerja

\begin{tabular}{|l|l|l|}
\hline Kriteria & Keterangan & Jenis \\
\hline $\mathrm{C}_{1}$ & Tanggung jawab & Benefit \\
\hline $\mathrm{C}_{2}$ & Kerjasama & Benefit \\
\hline $\mathrm{C}_{3}$ & Kualitas Hasil Pekerjaan & Benefit \\
\hline $\mathrm{C}_{4}$ & Kedisiplinan & Benefit \\
\hline $\mathrm{C}_{5}$ & Pelaporan & Benefit \\
\hline
\end{tabular}

Efektifitas Penilaian Kinerja Karyawan (Mesran) | 817 
Alternatif yang dihitung pada penelitian ini, hanya diambil dari beberapa karyawan, yaitu dari 5 karyawan. Berikut tabel 2 merupakan alternatif karyawan yang akan dinilai kinerjanya.

Tabel 2. Alternatif Karyawan

\begin{tabular}{|l|l|l|l|l|l|l|}
\hline Alternatif & Nama & $\mathbf{C}_{\mathbf{1}}$ & $\mathbf{C}_{\mathbf{2}}$ & $\mathbf{C}_{\mathbf{3}}$ & $\mathbf{C}_{\mathbf{4}}$ & $\mathbf{C}_{\mathbf{5}}$ \\
\hline $\mathrm{A}_{\mathbf{1}}$ & Sudirman & Sangat Baik & Sangat Baik & Baik & Baik & Baik \\
\hline $\mathrm{A}_{2}$ & Chairunisah Putri & Baik & Sangat Baik & Baik & Baik & Sangat Baik \\
\hline $\mathrm{A}_{3}$ & Muhammad Rifqy & Sangat Baik & Baik & Cukup & Sangat Baik & Baik \\
\hline $\mathrm{A}_{4}$ & Nurul Huda & Sangat Baik & Baik & Baik & Sangat Baik & Cukup Baik \\
\hline $\mathrm{A}_{5}$ & Triani & Baik & Baik & Baik & Baik & Sangat Baik \\
\hline
\end{tabular}

Berdasarkan tabel 2, terdapat nilai kriteria yang bersifat linguistik, sehingga diperlukan pembobotan terhadap nilai kriteria tersebut yang terlihat pada tabel 3 .

Tabel 3. Pembobotan nilai kriteria

\begin{tabular}{|l|l|}
\hline Keterangan & Bobot \\
\hline Sangat Baik & 5 \\
\hline Baik & 4 \\
\hline Cukup Baik & 3 \\
\hline Kurang Baik & 2 \\
\hline Tidak Baik & 1 \\
\hline
\end{tabular}

Setelah kriteria, alternatif dan pembobotan nilai alternatif terhadap kriteria dilakukan maka tahapan selanjutnya dengan menentukan bobot dan rating kecocokan. Berikut tabel 4, merupakan tabel yang berisikan rating kecocokan.

Tabel 4. Rating kecocokan

\begin{tabular}{|l|l|l|l|l|l|l|}
\hline Alternatif & Nama & $\mathbf{C}_{\mathbf{1}}$ & $\mathbf{C}_{\mathbf{2}}$ & $\mathbf{C}_{\mathbf{3}}$ & $\mathbf{C}_{\mathbf{4}}$ & $\mathbf{C}_{\mathbf{5}}$ \\
\hline $\mathrm{A}_{1}$ & Sudirman & 5 & 5 & 4 & 4 & 4 \\
\hline $\mathrm{A}_{2}$ & Chairunisah Putri & 4 & 5 & 4 & 4 & 5 \\
\hline $\mathrm{A}_{3}$ & Muhammad Rifqy & 5 & 4 & 3 & 5 & 4 \\
\hline $\mathrm{A}_{4}$ & Nurul Huda & 5 & 4 & 4 & 5 & 3 \\
\hline $\mathrm{A}_{5}$ & Triani & 4 & 4 & 4 & 4 & 5 \\
\hline
\end{tabular}

Untuk menghitung bobot, dengan menggunakan persamaan ke 3, yaitu:

$$
\begin{aligned}
& W_{1}=\frac{1+\frac{1}{2}+\frac{1}{3}+\frac{1}{4}+\frac{1}{5}}{5}=0,457 \\
& W_{2}=\frac{0+\frac{1}{2}+\frac{1}{3}+\frac{1}{4}+\frac{1}{5}}{5}=0,257 \\
& W_{3}=\frac{0+0+\frac{1}{3}+\frac{1}{4}+\frac{1}{5}}{5}=0,156 \\
& W_{4}=\frac{0+0+0+\frac{1}{4}+\frac{1}{5}}{5}=0,090 \\
& W_{5}=\frac{0+0+0+0+\frac{1}{5}}{5}=0,040
\end{aligned}
$$


Sehingga diperoleh nilai bobot dari setiap kriteria yang dibutuhkan, yaitu: $\mathrm{W}_{1}=0,457, \mathrm{~W}_{2}=0,257, \mathrm{~W}_{3}=0,156, \mathrm{~W}_{4}=0,090, \mathrm{~W}_{5}=0,040$. Total dari $\mathrm{W}$ pada setiap kriteria diharapkan bernilai 1 .

Berikut langkah yang dibutuhkan untuk penilaian kinerja karyawan dengan menerapkan metode ARAS.

a. Tahap awal malakukan perumusan terhadap Matriks Keputusan (dapat dilihat pada persamaan 4)

$$
X_{i j}=\left[\begin{array}{lllll}
5 & 5 & 4 & 5 & 5 \\
5 & 5 & 4 & 4 & 4 \\
4 & 5 & 4 & 4 & 5 \\
5 & 4 & 3 & 5 & 4 \\
5 & 4 & 4 & 5 & 3 \\
4 & 4 & 4 & 4 & 5
\end{array}\right]
$$

b. Tahap selanjutnya melakukan mormalisasi terhadap Matriks Keputusan (dapat dilihat pada persamaan 7).

Untuk Kriteria $\mathrm{C}_{1}$

$\mathrm{R}_{11}=5 / 28=0,1786$

$\mathrm{R}_{21}=4 / 28=0,1429$

$\mathrm{R}_{31}=5 / 28=0,1786$

$\mathrm{R}_{41}=5 / 28=0,1786$

$R_{51}=4 / 28=0,1429$

Sehingga untuk $\mathrm{R}_{01}$ merupakan maksimum dari kriteria 1, yaitu: 0,1786. Untuk menghitung $\mathrm{C}_{2}$ hingga $\mathrm{C}_{5}$, dilakukan langkah yang sama pada tahap 2. Hasil dari matrik yang telah dinormalisasikan, yaitu sebagai berikut.

$$
X^{*}=\left[\begin{array}{lllll}
0,1786 & 0,1852 & 0,1739 & 0,1852 & 0,1923 \\
0,1786 & 0,1852 & 0,1739 & 0,1481 & 0,1538 \\
0,1429 & 0,1852 & 0,1739 & 0,1481 & 0,1923 \\
0,1786 & 0,1481 & 0,1304 & 0,1852 & 0,1538 \\
0,1786 & 0,1481 & 0,1739 & 0,1852 & 0,1154 \\
0,1429 & 0,1481 & 0,1739 & 0,1481 & 0,1923
\end{array}\right]
$$

c. Tahap ke-3 melakukan matrik normalisasi terbobot (dapat dilihat pada persamaan 10).

Untuk Kriteria $\mathrm{C}_{1}$

$\mathrm{D}_{11}=0,1786 * 0,457=0,0816$

$\mathrm{D}_{21}=0,1429 * 0,457=0,0653$

$\mathrm{D}_{31}=0,1786 * 0,457=0,0816$

$\mathrm{D}_{41}=0,1786 * 0,457=0,0816$

$\mathrm{D}_{51}=0,1429 * 0,457=0,0653$ 
Sehingga untuk $\mathrm{D}_{01}$ merupakan maksimum dari kriteria 1, yaitu: 0,0816. Maka diperoleh matrik ternormalisasi terbobot yang dapat dilihat sebagai berikut:

$$
D=\left[\begin{array}{lllll}
0,0816 & 0,0476 & 0,0271 & 0,0167 & 0,0077 \\
0,0816 & 0,0476 & 0,0271 & 0,0133 & 0,0062 \\
0,0653 & 0,0476 & 0,0271 & 0,0133 & 0,0077 \\
0,0816 & 0,0381 & 0,0203 & 0,0167 & 0,0062 \\
0,0816 & 0,0381 & 0,0271 & 0,0167 & 0,0046 \\
0,0653 & 0,0381 & 0,0271 & 0,0133 & 0,0077
\end{array}\right]
$$

d. Tahap ke-4, yaitu menentukan fungsi optimalisasi $\left(\mathrm{S}_{\mathrm{i}}\right)$, dengan menjumlahkan nilai D pada setiap alternatif(dapar dilihat pada persamaan 11).

$$
\begin{aligned}
& S_{01}=0,0816+0,0476+0,0271+0,0167+0,0770=0,1807 \\
& S_{11}=0,0816+0,0476+0,0271+0,0133+0,0062=0.1758 \\
& S_{21}=0,0653+0,0476+0,0271+0,0133+0,0077=0,1610 \\
& S_{31}=0,0816+0,0381+0,0203+0,0167+0,0062=0,1628 \\
& S_{11}=0,0816+0,0381+0,0271+0,0167+0,0046=0,1681 \\
& S_{51}=0,0653+0,0381+0,0271+0,0133+0,0077=0,1515
\end{aligned}
$$

e. Tahap ke-5, merupakan langkah terakhir ditujukan untuk mencari peringkat terbaik $\left(\mathrm{U}_{\mathrm{i}}\right)$ (dapat dilihat pada persamaan 12)

$$
\begin{aligned}
& \mathrm{U}_{1}=0,1758 / 0,1807=0,97 \\
& \mathrm{U}_{2}=0,1610 / 0,1807=0,89 \\
& \mathrm{U}_{3}=0,1628 / 0,1807=0,90 \\
& \mathrm{U}_{4}=0,1681 / 0,1807=0,93 \\
& \mathrm{U}_{5}=0,1515 / 0,1807=0,84
\end{aligned}
$$

Dari perhitungan diatas hasil penilaian kinerja pada tabel berikut:

Tabel 5. Hasil akhir nilai kinerja karyawan

\begin{tabular}{|l|l|l|}
\hline Alternatif & Nama & Nilai (Ui) \\
\hline$A_{1}$ & Sudirman & 0.97 \\
\hline$A_{2}$ & Chairunisah Putri & 0.89 \\
\hline$A_{3}$ & Muhammad Rifqy & 0.90 \\
\hline$A_{4}$ & Nurul Huda & 0.93 \\
\hline$A_{5}$ & Triani & 0.84 \\
\hline
\end{tabular}

Dari tabel 5, kinerja karyawan yang paling rendah yaitu Triani $\left(A_{5}\right)$, sedangkan karyawan yang paling berkinerja baik yaitu Sudirman $\left(A_{1}\right)$.

\section{KESIMPULAN}

Dari penelitian yang dilakukan bahwa penilaian kinerja karyawa pada suatu perusahaan dengan menerapkan alat bantu, dalam hal ini sistem pendukung 
keputusan dapat memberikan hasil yang efektif terhadap informasi yang diperoleh bagi manajemen. Bobot yang dihasilkan dengan menggunakan metode ROC, dapat memberikan penilaian yang lebih bersifat objektif, bila dibandingkan dengan pemberian bobot langsung oleh pengambil keputusan.

\section{DAFTAR PUSTAKA}

[1] Y. Fernando, "Sistem Pendukung Keputusan Penilaian Kinerja Karyawan Menggunakan Metode Weighted Product di PT Makmur Jaya Kharisma," J-INTECH(Journal Inf. Technol., vol. 5, no. 2, pp. 40-43, 2017.

[2] S. Febrianti, M. Al Musadieq, and A. Prasetya, "Pengaruh Reward dan Punishment terhadap Motivasi Kerja serta Dampaknya terhadap Kinerja (Studi pada Karyawan PT . Panin Bank Tbk . Area Mikro Jombang)," J. Adm. Bisnis, vol. 12, no. 1, pp. 1-9, 2014.

[3] D. Nofriansyah and S. Defit, Multi Criteria Decision Making (MCDM) pada Sistem Pendukung Keputusan. 2018.

[4] D. Nofriansyah, Konsep Data Mining Vs Sistem Pendukung Keputusan. 2015.

[5] Kusrini, Konsep dan Aplikasi Sistem Pendukung Keputusan. Yogyakarta: Andi, 2007.

[6] G. Ginting, Fadlina, Mesran, A. P. U. Siahaan, and R. Rahim, "Technical Approach of TOPSIS in Decision Making," Int. J. Recent Trends Eng. Res., vol. 3, no. 8, pp. 58-64, 2017.

[7] S. H. Sahir et al., "The Preference Selection Index method in determining the location of used laptop marketing," Int. J. Eng. Technol., vol. 7, no. 3.4 Special Issue 4, 2018.

[8] S. H. Sahir, R. Rosmawati, and K. Minan, "Simple Additive Weighting Method to Determining Employee Salary Increase Rate," Int. J. Sci. Res. Sci. Technol., vol. 3, no. 8, pp. 42-48, 2017.

[9] J. Afriany, L. Ratna, S. Br, I. Julianty, and E. L. Nainggolan, "Penerapan MOORA Untuk Mendukung Efektifitas Keputusan Manajemen Dalam Penentuan Lokasi SPBU,” vol. 5, no. 2, pp. 161-166, 2018.

[10] K. Tangkuman, B. Tewal, and I. Trang, "PENILAIAN KINERJA, REWARD, DAN PUNISHMENT TERHADAP KINERJA KARYAWAN PADA PT. PERTAMINA (PERSERO) CABANG PEMASARAN SULUTTENGGO," EMBA, vol. 3, no. 2, pp. 884-895, 2015.

[11] S. Kusumadewi, S. Hartati, A. Harjoko, and R. Wardoyo, Fuzzy Multi-Attribute Decision Making (Fuzzy MADM). Yogyakarta: Graha Ilmu, 2006.

[12] N. Astiani, D. Andreswari, and Y. Setiawan, "Aplikasi Sistem Pendukung Keputusan Tanaman Obat Herbal Untuk Berbagai Penyakit Dengan Metode Roc (Rank Order Centroid) Dan Metode Oreste Berbasis Mobile Web," J. Inform., vol. 12, no. 2, 2016.

[13] Esra; and AyG̣egül, "AIR CONDITIONER SELECTION PROBLEM WITH COPRAS AND ARAS METHODS," Manas J. Soc. Stud., vol. 5, no. 2, 2016.

[14] E. K. Zavadskas and Z. Turskis, "A new additive ratio assessment ( ARAS ) method in multicriteria decision - making," vol. 8619, 2011.

[15] M. A. Hasma, B. Nadeak, N. Sitompul, and M. Mesran, "Sistem Pendukung Keputusan Penerimaan Instruktur Fitness Menerapkan Metode Additive Ratio Assessment (Aras) (Studi Kasus : Vizta Gym Medan)," KOMIK (Konferensi Nas. Teknol. Inf. dan Komputer), vol. 2, no. 1, pp. 121-129, 2018. 